\title{
HISTORIA SOBRE LOS CURSOS DE MÉXICO DE ESTUDIOS GENERALES
}

Reynaldo Sordo Cedeño*

RESUMEN: Una síntesis de la historia de los cursos de Historia Socio-Política de México y Problemas de la Realidad Mexicana Contemporánea: sus orígenes y gestación; los cambios que experimentaron; la motivación subyacente de los mismos y su finalidad: el compromiso que el estudiante tiene con la sociedad mexicana.

\section{yose}

ABSTRACT: We will give a summary of the history of the following courses: Mexico's SocioPolitical History and Contemporary Mexican Reality. Furthermore, we will delve into their origins and development, the changes they have gone through, their underlying motivation, and finally their goal: the student's commitment with Mexican society.

Palabras Clave: Historia de México, Problemas de México, Estudios Generales, Atlas histórico de México, Universidad.

KEY WORDS: Mexico's history, Mexico's problems, General Studies, Mexico's historical altas, University.

RECEPCIÓN: 28 de octubre de 2010.

APROBACIÓN: 7 de diciembre de 2010.

* Departamento Académico de Estudios Generales, ITAM. 
CITAM Derechos Reservados.

La reproducción total o parcial de este artículo se podrá hacer si el ITAM otorga la autorización previamente por escrito. 


\section{HISTORIA SOBRE LOS CURSOS DE MÉXICO DE ESTUDIOS GENERALES*}

Ma ás que hablar del Atlas quisiera compartir con ustedes algunos antecedentes históricos, al fin la deformación profesional se impone, sobre las materias de México que imparte el departamento de Estudios Generales, para que se pueda apreciar el contexto del cuál surgió el libro. La Dra. María Julia Sierra hablará más específicamente del Atlas.

El Lic. Javier Beristain escribía en 1979: “debemos comprender que nuestra labor educativa se hace en y por México, porque México nos duele y nos exige, porque el país requiere ser explicado en toda su variedad y complejidad". ${ }^{1}$

Un año después, el Lic. José Ramón Benito me invitó a incorporarme de tiempo completo al ITAM, después de haber trabajado como profesor de asignatura durante cinco años, desde Marina Nacional. Fueron los tiempos heroicos, cuando el ITAM era lo más parecido a una familia.

Recuerdo que una de las principales preocupaciones del Lic. Benito era la de poner en marcha una materia dedicada exclusivamente a México, porque hasta esas fechas los cursos de Ideas incorporaban, si no mal recuerdo, al final del programa, una serie de sesiones dedicadas al Pensamiento Mexicano. Ahí los alumnos entraban en contacto

* Conferencia dictada en la presentación del libro, Atlas de México. 1910/2010, el 27 de octubre de 2010 en el ITAM.

1 "La universidad mexicana y los problemas nacionales", en Javer Beristain, Saber para prever, prever para actuar. Ensayos y reflexiones acerca de la educación, 2009, México, ITAM, p. 160. 
REYNALDO SORDO

con los grandes pensadores mexicanos, desde la Ilustración hasta el siglo XX. En Ideas II, en un apartado sobre la Condición de los problemas, se estudiaba a Hipólito Villarroel, Mariano Otero y Luis G. Cuevas. En el apartado sobre Documentos los alumnos se acercaban al constitucionalismo mexicano del siglo XIX, desde la Constitución de Cádiz hasta las Leyes de Reforma; y en la sección Pensadores se analizaba el pensamiento de Francisco Javier Clavijero, Francisco Javier Alegre, Benito Díaz de Gamarra, José Joaquín Fernández de Lizardi, Fray Servando Teresa de Mier, Lucas Alamán, José María Luis Mora, José María Gutiérrez Estrada, Ignacio Ramírez, Francisco Zarco, Melchor Ocampo e Ignacio L. Vallarta, entre otros. Como se puede apreciar, se hacía un largo recorrido del pensamiento mexicano entre finales del siglo XVIII y la Reforma.

En Ideas III, la parte correspondiente a pensamiento mexicano se dividía en dos secciones: Los Pensadores, que abarcaba el análisis de las ideas de hombres como Justo Sierra, Pablo Macedo, José Yves Limantour, Andrés Molina Enríquez, Ricardo Flores Magón, Francisco I. Madero, Luis Cabrera, Rafael Nieto, Álvaro Obregón, Ramón López Velarde, Manuel Gamio, José Vasconcelos, Narciso Bassols, Antonio Caso, Vicente Lombardo Toledano, Manuel Gómez Morín, Luis González y muchos otros más. En la sección Documentos, se revisaban los principales planes de la Revolución mexicana y el Diario de Debates del Constituyente de 1916-1917. No mentía cuando les decía que eran los tiempos heroicos.

Gracias a la generosidad del maestro Benito, tuve el privilegio de formar el primer programa de una materia dedicada exclusivamente a nuestro país, que como materia optativa se impartió por primera vez en el semestre de agosto de 1980.

La materia fue bautizada como México: presente y pasado. La idea fue analizar el México contemporáneo a la luz de su trayectoria histórica reciente. El curso se dividió en siete grandes temas: visión general, la política, la economía y la sociedad, México y el ámbito internacional, México y los Estados Unidos, la cultura mexicana y una conclusión. ${ }^{2}$ En la Visión general los alumnos se acercaban a los aspectos básicos de la

${ }^{2}$ Programa de México: presente y pasado, agosto-diciembre de 1980. 
Geografía física del país y a los recursos naturales y el medio ambiente contemporáneos; en La política se estudiaba el Estado mexicano contemporáneo, el sistema político, los partidos políticos, el movimiento obrero, las organizaciones empresariales, la reciente reforma política de 1979 y las alternativas de la democracia; en Economía y socie$d a d$, se estudiaba el desarrollo económico general del país, se ponía énfasis en el problema del campo, la petrolarización de la economía, el desarrollo demográfico, la urbanización, la salud, seguridad social y nutrición, la educación pública y los viejos problemas y nuevas demandas de los grupos indígenas; en México y el ámbito internacional se analizaban las perspectivas de México en un mundo cambiante, las relaciones con los países del tercer mundo, México frente a Centroamérica, la inversión extranjera, la deuda externa y el comercio exterior; en México y los Estados Unidos el curso reconocía un lugar especial a la relación con nuestros vecinos del norte y se abordaban desde los conflictos culturales hasta los problemas concretos de esta difícil relación; en el tema de La cultura mexicana, se estudiaba el desarrollo cultural de México, desde el contacto entre la cultura española y la de los pueblos mesoamericanos, hasta nuestra cultura del siglo XX; y, finalmente, en la Conclusión, se pretendía que los alumnos encontraran sus propias respuestas y se comprometieran con el desarrollo de nuestro país. ${ }^{3}$

La materia se convirtió en obligatoria y cambió un poco su estructura. El temario se dividió en tres grandes apartados: introducción, ambiente físico y retrospectiva, y la realidad mexicana contemporánea. Además de ver la geografía mexicana, se dedicaron varias sesiones a la Historia de México: el mundo prehispánico, conquista y colonia, el México independiente y el México revolucionario, que antecedían al estudio de la realidad mexicana contemporánea. Posteriormente, México: presente y pasado cambió de nombre por el de Problemas de la Realidad Mexicana Contemporánea, $\mathrm{y}$, finalmente, en 1983 se formaron nuestros cursos de Historia Socio-Política de México y Problemas de la Realidad Mexicana Contemporánea ${ }^{4}$ Cuando se formó la materia de Historia se debatió

${ }^{3}$ Ibidem.

${ }^{4}$ Programa de México: presente y pasado, enero de 1982; Programa de Historia SocioPolítica de México, enero-mayo de 1983; y, Programa de Problemas de la Realidad Mexicana Contemporánea, enero-mayo de 1983. 
REYNALDO SORDO

sobre en qué etapa debería de comenzar y en cuál terminar. Las opiniones fueron variadas, pero al fin se impuso la sensatez y el curso comenzó con el mundo prehispánico, porque lo indígena es una parte esencial del ser de México, que no se debe obviar, sino por el contrario, darle un lugar preferente. El mismo Octavio Paz lo definió como "el hueso de México". Así, nuestro curso quedó estructurado en siete secciones: Mundo Prehispánico, Conquista y Colonia, Ilustración e Independencia, República y Reforma, República Restaurada y Porfiriato, Revolución de 1910, Reconstrucción Nacional (1920-1940). El curso de Problemas abordaría los grandes problemas nacionales contemporáneos de los últimos 40 años, aproximadamente. Debido a la reforma de las materias de Ideas, realizada en 1981-1982, las dos materias sobre México pudieron recuperar la riqueza del pensamiento mexicano, por medio de algunos de sus más importantes escritores que se encontraban en los cursos de Ideas y muchos otros nuevos que incorporamos: la leyenda de los soles, el diálogo de flor y canto, Bernal Díaz del Castillo, Fray Bartolomé de las Casas, Juan de Palafox y Mendoza, Carlos de Sigüenza y Góngora, Francisco Javier Alegre, Francisco Javier Clavijero, Melchor de Talamantes, Miguel Hidalgo, Miguel Ramos Arizpe, José María Morelos, Agustín de Iturbide, las Leyes de Reforma, André Molina Enríquez, Ricardo Flores Magón, Francisco I. Madero, los planes de la Revolución mexicana, el pacto de Xochimilco, Manuel Gómez Morín, Ramón López Velarde, José Vasconcelos, Plutarco Elías Calles, Lázaro Cárdenas, Jaime Torres Bodet, Antonio Carrillo Flores, Octavio Paz, Luis Villoro, Luis González, Carlos Monsivais y otros más. ${ }^{5}$

Los cursos nacieron y se desarrollaron dentro de los objetivos institucionales y los propios del Departamento de Estudios Generales. No se trataba de formar especialistas de la carrera de Historia, Geografía, Ciencia Política o cualquier otra, o tener contenidos que entraran en competencia o repitieran los de las otras ciencias. Reflexionar con los alumnos sobre nuestro pasado, desde el presente, para construir un futuro mejor. Reflexión seria, basada en textos de escritores reconocidos y representativos de cada una de las épocas estudiadas.

${ }^{5}$ Ibidem. 
En este sentido, rechazamos la historia positivista, la que busca el dato por el dato; el positivismo rankeano, que nos llevaría en el mejor de los casos a una erudición estéril y no a la comprensión y explicación de la realidad.

Nuestros cursos no podían contener la especialización llevada al extremo. Como estudiante en El Colegio de México, solíamos jugar con los títulos de las tesis doctorales de los norteamericanos: El impacto económico del ferrocarril mexicano en la región comprendida entre Río Blanco y Orizaba durante los años de 1880 y 1881.

Nuestros cursos también tendrían que presentar una pluralidad de opciones, que nos alejaran del pensamiento único y del oficialista, para que reflejaran la universalidad de nuestra Universidad. Siendo fieles al filósofo e historiador Benedetto Croce, quien afirma que "toda historia es historia contemporánea", pensamos que la relación entre nuestras dos materias tendría que ser indisoluble y nos veríamos obligados a reinventar el pasado desde nuestro presente y a definir el presente desde nuestro pasado. Entendimos que la línea que separa a las dos materias era intangible y variable.

En el fondo, lo que estaba y está en juego es el formar en los estudiantes una conciencia histórica y un acercamiento al conocimiento de nuestra Nación, para que se sientan parte de ella, para que valoren sus logros y analicen sus limitaciones y para que adquieran un compromiso con ella.

Nuestra reflexión histórica tenía, por lo tanto, que abrirse y alimentarse de la convivencia con otras ciencias y conocimientos: la Geografía, la Demografía, la Economía, la Sociología, la Antropología, el Derecho, la Política, las Relaciones Internacionales y las principales preocupaciones sociales y culturales. Formados, algunos de nosotros, en la Escuela de los Anales, queríamos que los alumnos entendieran los procesos de corta, mediana y larga duración. Aquí se inserta la elaboración de un auxiliar pedagógico como es el Atlas.

Hemos pretendido que los alumnos entendieran por lo menos dos ideas fundamentales:

a) Que el hombre es un ser histórico y que toda reflexión sobre el tiempo es una reflexión sobre el hombre. 
REYNALDO SORDO

b) Que formamos parte de una realidad histórica que se llama México, en la cual nacimos, vivimos y cuya existencia depende de lo que hagamos o dejemos de hacer.

Además, estas dos materias sobre México estaban al final del programa de Estudios Generales. Serían la coronación, la cereza del pastel. Tenía lógica, aquí tendrían que converger los conocimientos previos de Ideas y Problemas de la Civilización. Suponíamos que los alumnos habían alcanzado la madurez al llegar a ellas, entre el cuarto y sexto semestre, a la mitad de sus estudios. Pensamos siempre que, a estas alturas, tendrían un conocimiento y manejo del método dialógico que redundaría en el nivel de reflexión y compromiso.

Como ven, han sido muy altas nuestras expectativas. No sé si las hemos alcanzado y si los profesores hemos estado a la altura de ellas. Cuatro grandes reformas ha habido a lo largo de estos años y un sinnúmero de actualizaciones. Varios cientos de textos hemos utilizado.

Una vez, un profesor de asignatura de mucha confianza me comentó: "Historia está muy bien, no necesita cambiar". Mi respuesta fue tajante: "no has entendido nada. La Historia la rescribe cada generación y es tan cambiante como el presente mismo".

Grandes temas atraviesan los 45 siglos de nuestra historia:

1) La construcción de nuestro territorio y su diversidad

2) La importancia del México central y de la ciudad de México.

3) Los procesos demográficos.

4) La sobrevivencia de las comunidades indígenas.

5) Los grandes movimientos sociales

6) El papel de la Iglesia y de la religión católica en la construcción de nuestra identidad.

7) Las grandes revoluciones culturales: la evangelización del siglo XVI, la Ilustración, el liberalismo decimonónico, el positivismo, el vasconcelismo, el socialismo cardenista, la unidad nacional, la americanización de nuestra sociedad y la era global.

8) La formación de una sociedad desigual.

9) Las modernizaciones de las élites y sus efectos en una sociedad tradicional. 
10) La construcción del Estado nacional.

11) El divorcio entre gobernantes y gobernados.

12) Los efectos del contexto internacional en nuestro país.

13) La influencia de los Estados Unidos en el desarrollo de México.

Termino, nuevamente, con unas palabras del Lic. Beristain, escritas en México al filo del año 2000, de 1989:

Nuestro diario quehacer como escuela libre universitaria encuentra su razón de ser en los objetivos que nos hemos marcado y que proponen la formación integral de la persona humana y el desarrollo de una sociedad más libre, justa y próspera. Pretendemos en nuestra comunidad ITAM, el logro de una casa de estudio de excelencia, que con pleno apego a la libertad de cátedra y basada en su afán cotidiano de superación docente y continua investigación, logre formar hombres y mujeres capaces, críticos, responsables y comprometidos con la sociedad mexicana, a fin de alentarla en su desarrollo y bienestar social, cultural y económico. ${ }^{6}$

Estas dos materias del Departamento de Estudios Generales, al menos contribuyen al nivel más elemental: porque nadie ama ni se compromete por lo que no conoce.

En este sentido, el Atlas de México 1910/2010 no es solamente fruto de los esfuerzos de la Dra. Sierra y de un servidor, sino que recoge una larga tradición de muchos profesores comprometidos con el ITAM y con el Departamento Académico de Estudios Generales. Muchas gracias por su paciencia.

${ }^{6}$ México al filo del año 2000, 1989, México, ITAM, p. 7. 
CITAM Derechos Reservados.

La reproducción total o parcial de este artículo se podrá hacer si el ITAM otorga la autorización previamente por escrito. 